\title{
РЕДКИЕ МЕТАЛЛЫ В СОСТАВЕ ОТХОДОВ УНАЛЬСКОГО ХВОСТОХРАНИЛИЩА
}

\author{
И.3. Каманина ${ }^{1}$, М.В. Густова ${ }^{2}$ М.В. Фронтасьева ${ }^{3}$, \\ Н.Е. Пухаева ${ }^{4}$, С.П. Каплина
}

\begin{abstract}
Аннотация. Изучено содержание 16 редких металлов (титана, индия, теллура, селена, скандия, ванадия, рубидия, циркония, ниобия, молибдена, цезия, лантана, церия, тантала, тория и урана) в составе хвостов Унальского хвостохранилища Мизурской обогатительной фрабрики. Аналитические определения выполнены при помощи РФА и ИННА. На долю титана, индия, теллура и селена в составе хвостов приходится до 0,4 \%. По запасам индия, теллура, селена хвосты можно рассматривать как техногенные месторождения редких металлов. Ключевые слова: Северная Осетия, хвостохранилище, редкие металлы.
\end{abstract}

\section{ВВЕДЕНИЕ}

Редкие металлы - условное название группы металлов, перечень которых неоднократно менялся в течение последнего столетия [2]. Интерес к редким металлам связан с их использованием в новых технологиях и материалах. Масштабы производства и области применения их в высокотехнологичных отраслях продолжают быстро развиваться. Из 35 редких элементов 18 отнесены распоряжением Правительства РФ к стратегическим видам минерального сырья. Большинство стратегических редких металлов являются остродефрицитными для России, потребность в конечной продукции ниобия, тантала, редкоземельных металлов иттриевой группы, бериллия, рения, циркония, литиевом сырье удовлетворяется преимущественно за счет импорта [10]. Большинство редких металлов мало распространены, а часто и рассеяны в земной коре; их извлечение из сырья и получение в чистом виде связаны с большими технологическими трудностями. По литературным данным [3] такие редкие металлы как индий, таллий, селен и теллур содержатся во всех полиметаллических рудах Садонского рудного района, однако их качественная, количественная и экономическая оценка не производилась. Нет однозначной информации и об их извлечении на заводе «Электроцинк» при переработке свинцовых и цинковых концентратов.

С деятельностью горно-обогатительных комбинатов в Республике Северная Осетия-Алания связан целый ряд экологических проблем, в первую очередь это размещение и утилизация отходов переработки рудных материалов. В республике на площади 250 га накоплено 10 млн тонн металлосодержащих хвостов Мизурской и Фиагдонской обогатительных фабрик и металлургических заводов [4]. Одним из объектов экологической напряженности является Унальское хвостохранилище, на территории которого с 1984 г. размещаются отходы от переработки рудных материалов Мизурской обогатительной фабрики. А вместе с тем отходы добычи и переработки представляют собой техногенные месторождения полезных ископаемых.
Согласно справке Садонского свинцово-цинкового комбината (ССЦК) [13], в Унальском хвостохранилище накоплено 1140 тыс. тонн отходов обогащения с содержанием: свинца - 0,09 \%; цинка - 0,10\%; железа $3,5 \%$; кадмия - 0,001 \%; висмута - 0,002 \%. По другим данным [5, 12] объемы хвостов составляют от 2,6-3,2 млн тонн.

Вмещающими породами перерабатываемых руд являются граниты садонского типа, альбитофиры, конгломераты, кристаллические сланцы различного состава, кварциты, глинистые сланцы, габбро, алевролиты. Доля руд в альбитофирах, базальных конгломератах и кристаллических сланцах незначительна. Отходы Мизурской обогатительной фабрики содержат: глинистых сланцев - 7,57 \%, кварцитов 0,64 \%; граниты обнаружены в одной пробе из десяти в количестве 0,07 \%, алевролиты с карбонатным цементом - 0,3 \%, алевролиты - 0,14 \%, уплотненные глины - 0,07 \% [14].

В процессе первичной переработки выделяются отходы (хвосты), объемы которых составляют 60-95 \% (а для редких металлов и более) от всего объема перерабатываемой горной массы, т. е. значительно превосходят массу полезного компонента [14]. Как отмечают авторы в работе [6], промышленные отходы Мизурской горно-обогатительной фрабрики могут являться комплексным техногенным месторождением металлического и неметаллического сырья. Концентраты, получаемые в результате селективной фротации на Мизурской горно-обогатительной фабрике, содержат: $\mathrm{Pb}, \mathrm{Bi}, \mathrm{Sb}, \mathrm{Ag}, \mathrm{Au}, \mathrm{Cu}, \mathrm{Zn}, \mathrm{Co}, \mathrm{As}$ (свинцовый концентрат); Zn, Cd, Co, Pb, S, Sb, Ag, Fe, In (цинковый концентрат) [12].

В 2016 году кафедрой экологии и наук о Земле государственного университета «Дубна» совместно с Объединенным институтом ядерных исследований было проведено исследование элементного состава хвостов обогащения с Унальского хвостохранилища.

Цель настоящего исследования - определить содержание ряда редких металлов в составе отходов (хвостов) Мизурской обогатительной фрабрики, размещенных на территории Унальского хвостохранилища.

\footnotetext{
${ }^{1}$ Каманина Инна Здиславовна - к. б. н., доцент, кафедра экологии и наук о Земле, Государственное бюджетное образовательное учреждение высшего образования Московской области «Университет «Дубна», г. Дубна (kamanina@uni-dubna.ru).

${ }^{2}$ Густова Марина Владимировна - старший инженер, Лаборатория ядерных реакций им. Г.Н. Флерова ОИЯИ (gust@jinr.ru).

${ }_{3}^{3}$ Фронтасьева Марина Владимировна - к. ф.-м. н, начальник сектора нейтронного активационного анализа и прикладных исследований Лаборатории нейтронной физики им. И.М. Франка ОИЯИ (marina@nf.jinr.ru).

${ }^{4}$ Каплина Светлана Петровна - к. б. н., доцент кафедры экологии и наук о Земле, «Университет «Дубна» (sv_kap@mail.ru).

${ }^{5}$ Пухаева Нелли Ефримовна - к. фр.-м. н., cm.н. с. Лаборатории ядерных проблем им. В.П. Джелепова ОИЯИ (nelli.pukhaeva@gmail.com).

6 Чигоева Дзерасса Нугзаровна - аспирант кафредра экологии и наук о Земле «Университет «Дубна» (dzerkachigoeva@уаndex.ru).
} 


\section{ОБЪЕКТ ИССЛЕДОВАНИЯ}

Хвостохранилище расположено в центральной части Алагирского района, Республика Северная Осетия-Алания, в долине р. Ардон, на ее левом берегу между селениями Унал и Зинцар, в 12-15 км к северо-востоку от Мизурской обогатительной фабрики. Площадь хвостохранилища составляет около 20 га, глубина колеблется от 12 до 15 м. Большую часть поверхности хвостохранилища занимает пруд-отстойник. Выходы сухих хвостов в зависимости от количества подаваемой опресняющей воды изменяется от 3 до 100 м. По данным [13], минеральный состав отходов Мизурской фабрики представлен следующими минералами: кварц - 16,14 \%, полевые шпаты -отмечено присутствие амфиболов от знаков до 0,02 \%, знаки шпинели, пироксенов, ставролита, циркона, эпидота, сфена, гранатов, рутила, лейкоксена, анатаза. Отмечены незначительные содержания в отдельных пробах кальцита от $4,64 \%$ до 7,72 \%, сидерита от 1,2\% по 5,27 \%. Из минералов вредных примесей присутствуют: хлорит - 2,69 $\%$, пирит-марказит - 1,73\%, мусковит - 0,67\%, хлоритсерицитевые сланцы - 0,76

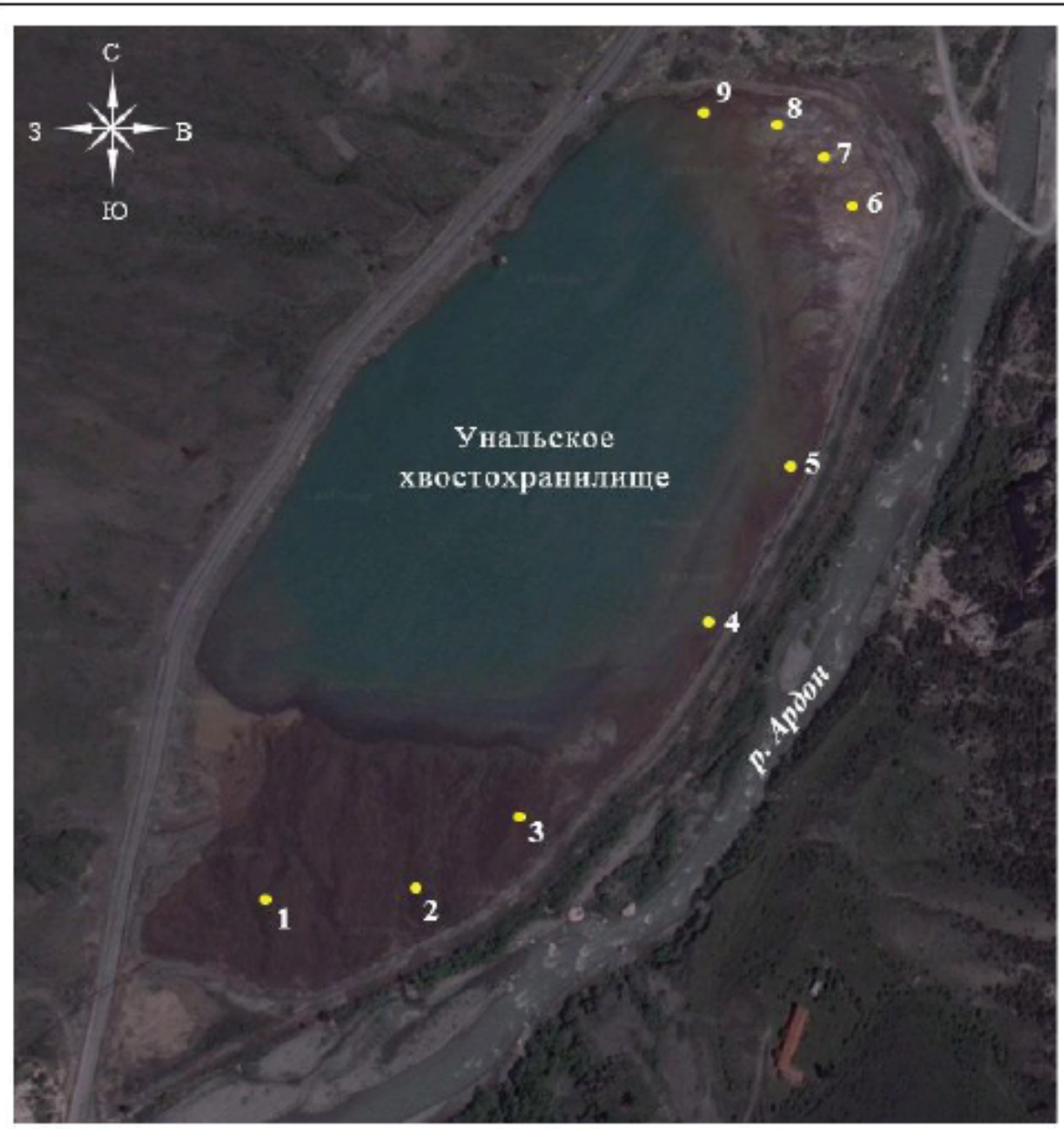

Масштаб 1:35000

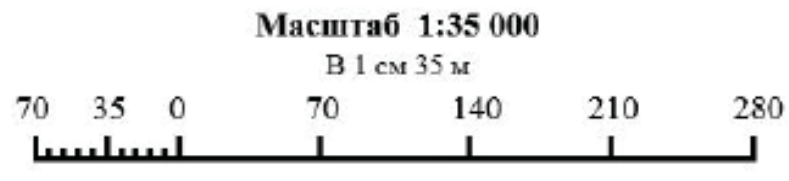

Puc. 1. Схема опробования Унальского хвостохранилища $\%$, пирротин - 0,57\%, соралерит - 0,11\%. Кроме того, встречается биотит, гидрослюды, галенит, арсенопирит, магнетит, гематит, металлическая стружка, барит, апатит, халцедон.

\section{МЕТОДЫ ИССЛЕДОВАНИЯ}

Опробование поверхности сухой части Унальского хвостохранилища проводили в 2015-2016 гг. Пробоотбор проводили в соответствии с общепринятыми методиками [9] в различных частях хвостохранилища. Всего было отобрано 9 проб: в южной части - точки 1-3, восточной - точки 4-6, северо-восточной - точки 7-9. Каждая проба формировалась путем смешивания 5 точечных проб, отобранных на глубину 0-10 см. Схема точек пробоотбора представлена на рис.1.

Аналитические определения были выполнены в Объединенном институте ядерных исследований (ОИЯИ), г. Дубна Московской области. Многоэлементное определение состава образцов рентгенофлуорес-

центным методом (РФА) проводилось в Лаборатории ядерных реакций им. Г.Н. Флерова (ЛЯР ОИЯИ), инструментальный нейтронноактивационный анализ (ИНАА - в Лаборатории нейтронной физики им. И.М. Франка (ЛНФ ОИЯИ).

Рентгеновские спектры образцов измерялись с помощью стандартного спектрометра фирмы Canberra. Для возбуждения рентгеновского излучения использовались кольцевые радиоизотопные источники $109 \mathrm{Cd}$ $(\mathrm{E}=22.16$ кэВ, Т1/2 = 453 дня) и 241Am $(\mathrm{E}=59,6$ кэВ, Т1/2 = 458 лет) с общей активностью 20 мКи. Характеристическое рентгеновское излучение регистрировалось полупроводниковым $\mathrm{Si}(\mathrm{Li})$ детектором с площа-

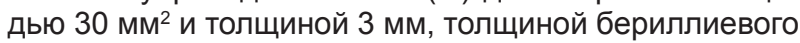
окна 25 мкм и с разрешением 145 эВ на линии 5,9 кэВ. Для обработки спектров и расчета концентраций элементов было использовано программное обеспечение для рентгенофлуоресцентного анализа Win Axil Canberra. Концентрации элементов определялись методом сравнения со стандартными образцами (ГСО) со схожими с определяемыми образцами матричными 
эфрфектами (СГ-1A, GnA, soil-5, GM, Sch-ST, $\mathrm{Fe}_{2} \mathrm{O}_{3}$ и др.). Для определения элементов, отсутствующих в эталонных образцах, была применена методика одновременного определения в насыщенных слоях вещества всех элементов, возбуждаемых радиоизотопными источниками, по единым калибровочным кривым, построенным на основании измерений стандартных образцов [11].

Инструментальный нейтронный активационный анализ (ИНАА) проводили на реакторе ИБР-2 ЛНФ ОИЯИ с использованием пневмотранспортной установки РЕГАТА [14].

Для определения короткоживущих изотопов элементов Ti, V, In образцы облучали 1 минуту в канале реактора с плотностью потока нейтронов 1,3 s 1012

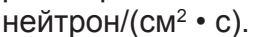

Для определения долгоживущих изотопов элементов Sc, Cs, La, Ce, Ta, Th, U образцы облучали около трех суток в канале реактора с кадмиевым экраном и плотностью потока резонансных нейтронов 1,6 s 1012 нейтрон/( $\left.\mathrm{cm}^{2} \bullet \mathrm{c}\right)$. После облучения образцы для измерения переупаковывали в чистые контейнеры. Наведенную гамма-активность образцов измеряли дважды: спустя 4-5 дней после выгрузки из канала облучения в течение 45 минут и спустя 20 дней в течение 1,5 часа. Для обработки гамма-спектров и расчета концентраций элементов использовали пакет программ, разработанных в ЛНФ ОИЯИ [7]. Качество анализа обеспечивалось с помощью сертифицированных эталонных материалов Coal fly ash (NIST, 1633c), Montana Soil (NIST, 2710), Estuarine sediment (BCR, 667), навески которых облучали в одинаковых условиях с исследуемыми образцами.

\section{РЕЗУЛЬТАТЫ ИССЛЕДОВАНИЯ И ОБСУЖДЕНИЯ}

Пробы, отобранные из сухой части Унальского хвостохранилища, представляют собой рыхлые техногенные породы.

Использование методов рентгенофлуоресцентного и нейтроноактивационного анализа позволило количественно определить в составе отходов Мизурской обогатительной фабрики, размещенных на территории Унальского хвостохранилища, содержание 16 редких элементов: титана, индия, теллура, селена, скандия, ванадия, рубидия, циркония, ниобия, молибдена, цезия, лантана, церия, тантала, тория и урана. Методом РФА были определены такие элементы, как: $\mathrm{Ti}, \mathrm{Te}, \mathrm{Zr}$, Ce, Rb, Nb, Мо, методом ИНAA: Ti, In, Se, V, Ce, La, Th, Sc, U, Ta и Cs.

Полученные данные были обработаны методами математической статистики с использованием программного пакета Microsoft Excel. Анализ полученных статистических параметров показал, что распределение данных по всем показателям отклоняется от нормального распределения, в качестве наиболее показательной описательной статистики является медиана, и именно она самым достоверным образом отражает положение центра вариационного ряда по всем показателям [8]. В качестве среднего по содержанию всех элементов принималось значение медианы.

Среднее содержание (медиана) элементов в тех- ногенных образованиях хвостохранилища (на глубине до 10 см) составляет (в порядке убывания), \%: Ті - 0,28; In - 0,07; Te - 0,056; Se - 0,01; Zr - 0,0044; V - 0,0034; Ce - 0,0033; La - 0,0025; Th - 0,0008; Sc - 0,0006; U - 0,0006; Cs - 0,00039; Rb - 0,0003; Nb 0,0003;Та - 0,0001; Мо - 0,0001 (табл.1). Суммарное содержание исследованных редких элементов в среднем составляет 0,413 \%, при этом 0,400 \% приходится на долю всего четырех элементов: титан, индий, теллур и селен.

На основе полученных данных по содержанию редких элементов были рассчитаны их запасы в хвостах (табл.1). Рассчитанные запасы можно рассматривать при условии, что высокое содержание элементов отмечается не только в верхней части хвостохранилища, но и на всю глубину.

Среднее содержание индия в верхней опробованной части хвостохранилища составляет около 700 г/т или $0,07 \%$. Его распределение крайне неравномерно - от 3 до 1200 г/т. Во всех точках опробования содержание индия превышает кларковое значение $(0,25$ $г / \mathrm{T})$, среднее содержание более чем в тысячу раз. Среднее содержание индия в техногенных образованиях хвостохранилища в сотни раз выше среднего содержания в промышленных рудах (полиметаллических, свинцово-цинковых, свинцовых, оловянно-свинцово-цинковых, медных и др.), которое соответствует 3,6 г/т [3]. По запасам индия месторождения более 500 т металла являются крупными. По приблизительным расчетам, запасы индия в хвостах Унальского хвостохранилища составляют 2100 т.

Содержание селена на разных участках опробования колеблется от 9 до 790 г/т, в среднем составляет 103 г/т, что более чем в 2000 раз превышает кларковое значение. Промышленные селеносодержащие руды (медные, медно-цинковые, медно-никелевые, медно-молибденовые, полиметаллические, свинцовоцинковые) по содержанию селена (г/т) подразделяются на богатые - 120, средние - 60, бедные - 20 [3]. Таким образом, хвосты по содержанию селена соответствуют богатым рудам. Запасы селена в хвостах составляют около 309 т.

Среднее содержание теллура в хвостах находится на уровне 456 г/т и превышает кларковое значение $(0,001$ г/т) в сотни тысяч раз. Теллур - рассеянный элемент, не образует собственных месторождений. Встречается в полиметаллических и свинцово-цинковых залежах.

Среднее содержание в составе хвостов таких редких металлов, как титан, скандий, ванадий, ниобий, молибден, лантан, церий, технеций, скандий, не превышает кларковых значений, при этом максимальное содержание находится на уровне кларков или незначительно превышает его. Содержание рубидия и циркония в хвостах ниже кларков в десятки раз. Содержание рубидия и циркония крайне неравномерно и колеблется для рубидия от 3 до 128 г/т, среднее 31,1 г/т, для циркония - от 15 до 131г/т, среднее содержание - 11,63 г/т. Содержание тантала в образцах изменяется незначительно - от 0,39 до 2,2 г/т, среднее составляет 1,2 г/т, или $0,00012 \%$, что соответствует бедным рудам.

Содержание ниобия и молибдена в хвостах зна- 
Таблица 1

Результаты анализа хвостов Унальского хвостохранилиша

\begin{tabular}{|c|c|c|c|c|c|c|c|}
\hline \multirow[t]{2}{*}{ Элемент } & \multirow[t]{2}{*}{$\begin{array}{l}\text { Метод } \\
\text { анализа }\end{array}$} & Минимум & Максимум & Среднес & Медиана & $\begin{array}{c}\text { Кларк в земной } \\
\text { коре по } \\
\text { Виноградову[1] }\end{array}$ & \multirow[t]{2}{*}{$\begin{array}{c}\text { Запасы в } \\
\text { хвостах, } \\
\text { т. }\end{array}$} \\
\hline & & \multicolumn{5}{|c|}{ Содержание элемента, г/т, ppm } & \\
\hline $\mathrm{Ti}$ & $\begin{array}{l}\text { РФА } \\
\text { ИНАA* }\end{array}$ & 2000 & 4000 & 2770 & 2800 & 4500 & 8400 \\
\hline In & ИНАА & 3,0 & 1200 & 590 & 700 & 0,25 & 2100 \\
\hline $\mathrm{Te}$ & PФA & 9,0 & 770 & 399 & 456 & 0,001 & 1368 \\
\hline Se & ИНАA & 9,0 & 890 & 320 & 103 & 0,05 & 309 \\
\hline $\mathrm{Zr}$ & PФA & 15,0 & 131 & 51,3 & 44,0 & 170 & 34,87 \\
\hline V & ИНАA & 18,7 & 103 & 45,5 & 33,7 & 90 & 101,1 \\
\hline $\mathrm{Ce}$ & $\begin{array}{l}\text { РФА } \\
\text { ИНAA* }\end{array}$ & 6,0 & 66,0 & 33,7 & 33,0 & 70 & 99 \\
\hline $\mathrm{La}$ & ИНАА & 5,9 & 40,0 & 24,1 & 25 & 29 & 75 \\
\hline Th & ИНАА & 3,7 & 13,7 & 8,39 & 8,0 & 13 & 24 \\
\hline $\mathrm{Sc}$ & ИНАА & 3,3 & 9,6 & 6,12 & 6,0 & 10 & 18 \\
\hline U & ИНАА & 2,5 & 10,0 & 5,77 & 6,2 & 2,5 & 18,6 \\
\hline $\mathrm{Rb}$ & $\mathrm{P} Ф \mathrm{~A}$ & 3,0 & 128 & 31,1 & 3,0 & 150 & 9 \\
\hline $\mathrm{Nb}$ & РФА & 1,0 & 10,0 & 3,55 & 3,0 & 20 & 9 \\
\hline $\mathrm{Ta}$ & ИНАА & 0,39 & 2,2 & 1,29 & 1,2 & 0,7 & 3,6 \\
\hline Mo & РФА & 1,0 & 8,0 & 2,22 & 1,0 & 1,1 & 3 \\
\hline $\mathrm{Cs}$ & ИНАА & 1,8 & 7,3 & 4,03 & 3,9 & 3,7 & 12,79 \\
\hline
\end{tabular}

* Результаты, полученные при помощи РФА и ИНАА, совпадают в пределах ошибок определения.

чительно ниже содержания в промышленных рудах. Ниобия - на уровне 3 г/т (0,0003\%), бедные промышленные руды содержат 0,15-0,03\% $\mathrm{Nb}_{2} \mathrm{O}_{5}$. Молибдена - от 1 до 8 г/т, что значительно ниже, чем в бедных промышленных рудах (0,001\% Мо).

Bce вышеперечисленные элементы обладают высокой токсичностью, даже такие жизненно необходимые микроэлементы, как селен. Присутствие их в составе рыхлых техногенных пород, подверженных дефляции, представляет высокую опасность для окружающей среды.

Высокое содержание в составе хвостов Унальского хвостохранилища индия, селена, теллура позволяет рассматривать их как техногенные месторождения полезных ископаемых. Результаты, полученные авторами, указывают на необходимость более детального обследования состава отходов на всю глубину и с увеличением точек опробования.

По данным [4], запасы техногенных месторождений в РСО-А составляют 10 млн тонн. Необходимо провести оценку ресурсного потенциала отходов ССЦК с учетом возможности использования как нетрадиционного сырья для получения редких металлов. По сложности геологического строения для целей разведки Унальское хвостохранилище можно отнести к простым по строению, с выдержанным качеством полезного ископаемого.

Большинство редкометалльных объектов России не осваиваются из-за их низкой рентабельности. При- менение инновационных технологических решений позволит использовать имеющиеся в хвостах запасы редких металлов и ликвидировать очаг экологической напряженности в РСO-А.

\section{ВЫВОДЫ}

Суммарное содержание Ti, In, Te, Se, Zr, V, Ce, La, Th, Sc, U, Rb, Nb, Ta, Mo, Cs в составе техногенных образований составляет в среднем 0,413 \%. На долю таких элементов как Ti, In, Те и Se приходится до 0,400 \%. Zr, V, Ce, La, Th, Sc, U, Rb, Nb, Ta, Mo, Cs составляют $0,013 \%$.

1. Содержание индия, селена, теллура в составе хвостов Унальского хвостохранилища превышает кларковые в тысячи и сотни тысяч раз (Те - в 456000 раз; In - 2400 раз; Se - 2 060).

2. Отходы переработки Мизурской горно-обогатительной фабрики можно отнести к техногенным месторождениям с запасами металлов: индия - 2100 т, теллура - 1368 т, селена - 309 т, при условии, что высокое содержание элементов отмечается не только в верхней части хвостохранилища, но и на всю глубину.

3. Высокое содержание редких металлов в рыхлых техногенных образованиях Унальского хвостохранилища представляет токсикологическую опасность для окружающей среды. 


\section{ЛИТЕРАТУРА}

1. Алексеенко В.А. Экологическая геохимия / В.А. Алексеенко. - М.: Логос, 2000. 627с.

2. Быховский Л.3. Об определении понятия «редкие элементы» (редкие металлы): исторический и терминологический аспекты / Л.З. Быховский, Л.П. Тигунов // Минеральные ресурсы России. Экономика и управление, 2015. № 3.С. 32-39.

3. Геология и полезные ископаемые / В. Б. Цогоев (отв. ред.) и др. - Владикавказ: Проект-Пресс, 2005 (Владикавказ:ИПП им. В.А. Гассиева). 390 с.

4. Голик В.И. Экономическая эфрфективность предупреждения природно-техногенных катастрофр в горнодобывающих реги онах / В.И. Голик, Е.В. Козырев, Е.Н. Клочко, Я.Г. Небывалова // Научный вестник ЮИМ, 2015. № 3. С. 7-13.

5. Голик В.И. Перспективы возрождения горного производства Северной Осетии / В.И. Голик, Т.М. Тезиев // Актуальные вопросы современной науки, 2016. № 45. С. 110-121.

6. Гурбанов А.Г. Промышленные отходы Мизурской горно-обогатительной фабрики Садонского свинцово-цинкового комбината (геохимические особенности, оценка их воздействия на экологическую обстановку прилегающих территорий (почвы и воду р. Ардон), Республика Северная Осетия-Алания / А.Г. Гурбанов, Ю.К. Шаззо, А.Б. Лексин, В.М. Газеев, А. Я. Докучаев, Л.Е Цуканова, Я.И. Якушев, И.С. Семенова, С.И. Исаков // Вестник Владикавказкого научного чента. 2012. Т. 12. № 4. С. 27-40.

7. Дмитриев А.Ю., Павлов С.С. Автоматизация количественного определения содержания элементов в образцах методом нейтронного активационного анализа на реакторе ИБР 2 в ЛНФ ОИЯИ/ А.Ю. Дмитриев, С.С. Павлов // Письма в
ЭЧАЯ, 2013. Т. 10. № 1 (178). С. 58-64.

8. Дмитриев Е.A. Математическая статистика в почвоведении, 3-е изд. / Е.А. Дмитриев. - М.: Либроком, 2009. 328 с.

9. Карпов Ю.А. Методы пробоотбора и пробоподготовки / Ю.А. Карпов, А.П. Савостин. - М.: Бином. Лаборатория знаний, 2003. $243 c$

10. Кременецкий А.А. ИМГРЭ - редкие металлы: прошлое, настоящее, будущее / А.А. Кременецкий, Н.А. Архипова, И.Е. Максимюк, Т.Ю. Усова // Разведка и охрана недр, 2010. № 12. C. $80-87$.

11. Маслов О.Д. Многокомпонентный инструментальный рентаенофлюоресцентный анализ почв и других объектов окружающей среды на токсичные и сопутствующие элементы / О.Д. Маслов, М.В. Густова, Л.Г. Молоканова // Стандарт предприятия СТП 104-2002, ОИЯИ. - Дубна, 2002. 16 с.

12. Пряничникова Е.В. Эколого-геохимическая оценка горнорудного района: На примере Садоно-Унальской котловины, Республика Северная Осетия-Алания: автореферат дис.кандидата геолого-минералогических наук : 25.00.09/Моск. гос. ун-т им. М.В. Ломоносова. Геол. фрак. - Москва. 2005. 27 с.

13. Рухлин Г.В. Отходы горного производства как сырье для высокотехнологичной продукции / Г.В. Рухлин, А.М Байматов // Вестник Северо-Кавказского государственного технического университета. - 2010. №4(25).C. 34-39.

14. Фронтасьева М.B. REGATA Experimental Setup for Air Pollution Studies / M.В. Фронтасьева, С.С. Павлов // Всб. «Проблемы современной физики». Под редакцией А.Н. Сисакяна и В.И. Трубецкова. - Дубна, ОИЯИ, 1999. С. 152-158.

\section{RARE METALS IN THE WASTE OF THE UNAL TAILINGS. NORTH OSSETIA I.Z. Kamanina ${ }^{1}$, M.V. Gustova ${ }^{2}$, M.V. Frontasyeva ${ }^{2}$, N.E. Pukhaeva ${ }^{2}$, S.P. Kaplina ${ }^{1}$, D.N. Chigoeva ${ }^{1}$}

\footnotetext{
${ }^{1}$ State budgetary educational institution of higher education of the Moscow region "University «Dubna», Dubna Moscow region

2 Joint Institute for Nuclear Research, Dubna, Moscow region.
}

Abstract. The content of 16 rare metals (titanium, indium, tellurium, selenium, scandium, vanadium, rubidium, zirconium, niobium, molybdenum, cesium, lanthanum, cerium, tantalum, thorium and uranium) at the Unal tailings of the Mizur concentrating factory has been studied. Analytical definitions are made by the use of XFA (X-ray fluorescence analysis) and INNA. Titanium, indium, tellurium and selenium in the tailings account for up to $0.4 \%$. By reserves of indium, tellurium, selenium, the tails can be considered as technogenic deposits of rare metals.

Keywords: North Ossetia, tailing pond, rare metals.

\section{REFERENCES}

1. Alekseenko V.A. EHkologicheskaya geohimiya / V.A. Alekseenko. - M.: Logos, 2000. 627s.

2. Byhovskij L.Z. Ob opredelenii ponyatiya "redkie ehlementy" (redkie metally): istoricheskij i terminologicheskij aspekty / L.Z. Byhovskij, L.P. Tigunov // Mineral'nye resursy Rossii. EHkonomika i upravlenie, 2015. № 3.S. 32-39.

3. Geologiya i poleznye iskopaemye / V.B. Cogoev (otv. red.) i dr. Vladikavkaz: Proekt-Press, 2005. 390 s.

4. Golik V.I. EHkonomicheskaya ehffektivnost' preduprezhdeniya prirodno-tekhnogennyh katastrof $v$ gornodobyvayushchih regionah V.I. Golik, E.V. Kozyrev, E.N. Klochko, YA.G. Nebyvalova // Nauchnyj vestnik YUIM, 2015. № 3. S. 7-13.

5. Golik V.I. Perspektivy vozrozhdeniya gornogo proizvodstva Severnoj Osetii / V.I. Golik, T.M. Teziev // Aktual'nye voprosy sovremennoj nauki, 2016. № 45. S. 110-121.

6. Gurbanov A.G. Promyshlennye othody Mizurskoj gorno-obogatitel'noj fabriki Sadonskogo svincovo-cinkovogo kombinata (geohimicheskie osobennosti, ocenka ih vozdejstviya na ehkologicheskuyu obstanovku prilegayushchih territorij (pochvy i vodu r. Ardon), Respublika Severnaya Osetiya-Alaniya / A.G. Gurbanov, YU.K SHazzo, A.B. Leksin, V.M. Gazeev, A. YA. Dokuchaev, L.E. Cukanova, YA.I. YAkushev, I.S. Semenova, S.I. Isakov // Vestnik Vladikavkazkogo nauchnogo centa. 2012. T. 12. № 4. S. 27-40.

7. Dmitriev A.YU., Pavlov S.S. Avtomatizaciya kolichestvennogo opredeleniya soderzhaniya ehlementov $v$ obrazcah metodom nejtronnogo aktivacionnogo analiza na reaktore IBR 2 v LNF OIYAI/ A. YU. Dmitriev, S.S. Pavlov // Pis'ma v EHCHAYA, 2013. T. 10. №
1 (178). S. 58-64.

8. Dmitriev E.A. Matematicheskaya statistika v pochvovedenii, 3-e izd. / E.A. Dmitriev. - M.: Librokom, 2009. 328 s.

9. Karpov YU.A. Metody probootbora i probopodgotovki / YU.A. Karpov, A.P. Savostin. - M.: Binom. Laboratoriya znanij, 2003. 243 s. 10. Kremeneckij A.A. IMGREH - redkie metally: proshloe, nastoyashchee, budushchee / A.A. Kremeneckij, N.A. Arhipova, I.E. Maksimyuk, T.YU. Usova // Razvedka i ohrana nedr, 2010. № 12. S. 80-87. 11. Maslov O.D. Mnogokomponentnyj instrumental'nyj rentgenoflyuorescentnyj analiz pochv $i$ drugih ob»ektov okruzhayushchej sredy na toksichnye $i$ soputstvuyushchie ehlementy / O.D. Maslov, M.V. Gustova, L.G. Molokanova // Standart predpriyatiya STP 1042002, OIYAl. - Dubna, 2002. $16 \mathrm{~s}$.

12. Pryanichnikova E.V. EHkologo-geohimicheskaya ocenka gornorudnogo rajona: Na primere Sadono-Unal'skoj kotloviny, Respublika Severnaya Osetiya-Alaniya: avtoreferat dis.kandidata geologomineralogicheskih nauk : 25.00.09 / Mosk. gos. un-t im. M.V. Lomonosova. Geol. fak. - Moskva. 2005. 27 s.

13. Ruhlin G.V. Othody gornogo proizvodstva kak syr'e dlya vysokotekhnologichnoj produkcii / G.V. Ruhlin, A.M Bajmatov // VestnikSevero-Kavkazskogo gosudarstvennogo tekhnicheskogo universiteta. - 2010. №4(25). S. 34-39.

14. Frontas'eva M.V. REGATA Experimental Setup for Air Pollution Studies / M.V. Frontas'eva, S.S. Pavlov // Vsb. "Problemy sovremennoj fiziki». Pod redakciej A.N. Sisakyana i V.I. Trubeckova. Dubna, OIYAl, 1999. S. 152-158. 